Sristi Kamal, Marcin Kocór,

Małgorzata Grodzińska-Jurczak

Jagiellonian University, Poland

\section{Quantifying Human Subjectivity Using Q Method: When Quality Meets Quantity}

Abstract Incorporating human subjectivity in applied disciplines of social sciences and other base sciences poses a challenge as the nature of qualitative data is often the point of contention. $Q$ methodology is a tool that addresses this challenge as it helps quantify qualitative data using $Q$ factor analysis. Initially developed for psychology and political sciences, $Q$ methodology now finds its use in many research disciplines of science, especially in interdisciplinary studies that take into account human subjectivity. This article provides a detailed description on the various steps involved in conducting a $Q$ study, with special emphasis on data interpretation. To describe the methodology and demonstrate data interpretation, we used data from our pilot case study of socio-ecological nature that documents attitudes of people towards nature conservation on private land. Additionally, we mention the specific usefulness of this method, highlight the potential challenges at each step of the approach, and provide practical advice to overcome them. In our opinion Q methodology has been more restricted in its use on the ground of being a more social or psychological tool, and therefore, our aim is to familiarize researchers who could be interested in a mixed approach of joining quantitative data analysis with qualitative, in-depth interpretation with the approach at hand.

Keywords Q methodology; Human Subjectivity; Attitudes Categorization; Methodology Description; Mixed Approach

\section{Introductory Remarks}

\section{Interdisciplinary and Q Methodology}

Documenting human subjectivity in an objective manner has always been a point of contention in scientific research. Research disciplines such as psychology, political science, social anthropology, and other social sciences have relied on qualitative methods such as observations, interviews, and discussions. However, the various tools of qualitative research are often criticized for lack of reliability, being time consuming, and having a higher scope of bias because of subjectivity (Miles and Huberman 1994; Woods 2006; Maison 2007). These very reasons also make it a challenge to integrate human subjectivity into other research fields that could benefit from such knowledge, and the field of environmental sciences is one such example. This paper identifies $Q$ methodology as one of the potential tools that can help to fill the existing lacunae in incorporating social science knowledge into environmental conservation strategies.

Environmental science is often regarded as a branch of life or earth sciences that rely mostly on biology, ecology, or geography, and their applied branches (Irwin 2001). Specifically, natural resource management (including biological diversity) has benefitted a lot from the knowledge and research embedded within the area of these subjects. However, until the last couple of decades, the role of human dimensions in sustainable natural resource management was often undermined, but now there is a growing recognition which makes it imperative to embed the field of social sciences, along with environmental economics, for a more holistic view that takes into account all dimensions that influence nature (Manfredo et al. 1995; Manfredo and Dayer 2004; Heberlein 2012). Without taking human needs and expectations into account, strategies that are focused on managing natural resources face tough challenges in practical implementation. However, methodologies that would allow the collection and use of such social data in environmental sciences are still very limited.

Q methodology, in its simplest definition, helps quantify human subjectivity in a way that allows for statistical interpretation while leaving the scope for in-depth, qualitative interpretation. It thus views the issue at hand from the internal standpoint of the person being studied. This viewpoint gets a meaning only when the analysis is over, as opposed to having pre-defined clusters of opinions to categorize people into. It can be considered as the bridge between qualitative and quantitative research in that it touches on both dimensions of research tools and brings together the strength of the two (Sell and Brown 1984). The aim of this article is to give a detailed account of the various steps involved in conducting a $Q$ study (including data interpretation), with the help of a pilot case study that we conducted in Poland among students of environmental protection, which uses this methodology in a socio-environmental context. It also highlights the limitations and the precautionary steps to be taken in order to maximize the benefits of using such a method in interdisciplinary studies.

\section{Q Methodology: Its Origin and Applications}

Q method was developed for the first time in the 1930s by William Stephenson, a psychologist and 
physicist, to primarily document human subjectivity (Stephenson 1935; Brown 1980; Cross 2005). The impetus behind developing a methodology such as the $\mathrm{Q}$ technique was to reveal the subjectivity in opinions/attitudes of people involved in a given situation. While the main goal in carrying out a study using $\mathrm{Q}$ methodology is to document subjective (and therefore, qualitative) opinion, the tools used to do so are often associated with quantitative skills due to their use of factor analysis (Brown 1996).

In a short summary, $\mathrm{Q}$ methodology is a procedure whereby a sample of objects (usually statements) that respond to one particular question is put in a pre-described order based on their importance or relevance to the respondent. The main aim at the end of conducting a $Q$ methodology is to emerge with distinct typologies of attitudes (but not groups of people) among the group of sampled respondents. Here, the $\mathrm{Q}$ statements are the subjects and the variables are the $\mathrm{Q}$ sorts (statement ranking generated by each respondent) (Webler, Danielson, and Tuler 2009). Without seeking a direct "yes" or a "no" for a question (and thus, limiting the preference to either of the two opinions), it derives the various dimensions in opinions on the subject. It is important to remember that $\mathrm{Q}$ method does not aim at inferring the population; rather it focuses on covering the diverse range of views expressed, and not at the percentage of people expressing them.

Although the use of $\mathrm{Q}$ methodology was initially aimed at measuring attitudes of people in psychological studies, since that time, it has spread in many other fields of research in base science, med- icine, and social sciences (Brown 1996). Subjective opinions of people hold importance in almost all aspects of scientific application, and with few tools around for quantifying opinions, Q methodology is gaining in popularity. Since its first description and practical application, $\mathrm{Q}$ methodology has been applied in various fields of social sciences such as political science, applied psychology, communication, and behavioral studies (Cross 2005; Watts and Stenner 2005). As rightly put by Brown, $Q$ can find its use in almost every situation involving perception - "in aesthetic judgment, poetic interpretation, perceptions of organizational role, political attitudes, appraisals of health care, experiences of bereavement" (1996:563), and the list is endless. Indeed, $\mathrm{Q}$ methodology is now being used extensively in health care and promotion, health information techniques and education (Brown 1996; Cross 2005; Deignan 2009; Spurgeon et al. 2012).

Specifically in the case of socio-environmental studies, $Q$ could form an important platform that supports the growing need for socio-ecological research, such as studies conducted by Steelman and Maguire (1999), Nijnik and colleagues (2010), Sandbrook and colleagues (2010), and Ray (2011), to name a few. Incorporating social sciences knowledge is also crucial for managing or mitigating different forms of human-nature conflict, which is a result of increasing demographic and economic pressure on limited natural resources (Manfredo and Dayer 2004). An example of such conflicts is the case of a recent implementation of nature conservation policies such as the EU Ecological Network of Special Areas of Conservation (popularly known as Natura 2000), which is being implemented in all EU Mem- ber States, Poland being no exception (Grodzińska-Jurczak 2008; Grodzińska-Jurczak et al. 2012a; Pietrzyk-Kaszyńska et al. 2012; Cent, Mertensa, and Niedziałkowski 2013). In fact, the case in example discussed in this paper to describe the use and interpretation of $\mathrm{Q}$ methodology represents a pilot study of a research that focuses on one of such issues: assessing stakeholders' attitude towards inclusion of private land in protected areas for biodiversity conservation.

\section{Q Methodology: Description of the Entire Procedure}

This article takes a different standpoint from other descriptions of $\mathrm{Q}$ methodology, such as Van Exel and De Graaf (2005) and Shinebourne (2009), in this sense that the entire methodology description will be supported by an example for better understanding of the different steps of conducting $\mathrm{Q}$. The pilot study that has been used to describe the methodology is a part of ongoing research in Poland that attempts to describe stakeholders' perspectives on the challenges and opportunities that lie in private land conservation. Nature conservation (including biodiversity conservation) has relied heavily on protected areas, but as the global threats to natural resources continue, the number, as well as nature of protected areas, needed to evolve. As a result, countries are increasing the percentage of their territory under protection by raising the number of protected areas, and also the type of protected area. Designation of protected areas usually relies on their ecological significance determining their conservation potential, thereby it ignores the nature of ownership of the land (Grodzińska-Jurczak and Cent 2011; Grodzińska-Jurczak et al. 2012b). As a result, protected areas sometimes engulf private land. Specifically in Poland, in addition to national parks and other protected areas, Natura 2000 is adding considerable amounts of private land into protected areas. This, of course, generates potential conflict issues between landowners and other stakeholders, such as financial loss, loss of authority over deciding land use, contention of property rights, to name a few (Clough 2000; Grodzińska-Jurczak et al. 2012a). It is therefore imperative to evaluate different stakeholders' perceptions of including private land in protected areas.

\section{Preparing the $Q$ Statements}

The first stage of $Q$ methodology involves defining the exact research question that needs to be addressed. Q statements usually respond to one specific question or complete a half-phrased statement. Once the main question/statement is defined, the next step is to prepare the statements list, which is one of the most crucial steps in the whole process.

The procedure of preparing $Q$ statements set can follow either of the two possible paths: unstructured or structured approach (Watts and Stenner 2012). The unstructured method does not follow specific dimensions; rather, it just gives broader general ideas, and as such is advised for basic research only. The structured approach involves identifying different dimensions which form the basis of drafting statements, that is, they are the broader guiding themes within the topic that the Qstudy should explore. For instance, while drafting 
the statements for our research, the identified dimensions were attitude of stakeholders towards private land in conservation, awareness of potential conflict, and attitude towards exploring potential solutions, with reasons behind each expressed attitude (economic/financial, personal/social, decision-making/policy driven). It is not necessary to have equal numbers of statements in each dimension; however, Brown (1980) gave some examples of "balanced-block" being more effective.

The most crucial part in preparing statements is to cover all spectrums of issues related to that topic from all possible and available sources. Sources could include secondary data, such as official documents, newspapers, results of previous research (e.g., some statements from scales used in different studies), and/or primary data, such as IDI (In-Depth Interviews) or FGD (Focus Group Discussions [with members of the participant's groups]). A typical Q study can have statements ranging from anywhere from 30 to 60 , although lesser or higher numbers than these are also possible (Kerlinger 1969; Curt 1994; Stainton Rogers 1995). However, having a large number of statements poses a challenge in the sorting process for respondents and in the interpretation process for the researcher. In our opinion, the number of statements used in a $Q$ set should be a matter of pragmatism. Emphasis should be on the right construction of items and adequate coverage of all topics, attitudes, or points of view of all groups of participants rather than focusing on the number of statements. In the case study presented as an example here, the statements were prepared on the basis of secondary sources. These included conclusions of scientific research articles on the topic, articles in popular magazines, discussions and interviews in international and national newspapers, Internet websites and forums. For the first phase, 48 statements were drafted. They were then evaluated based on similarity, dissimilarity, and having double meanings. This process was repeated twice by the authors, leading to a final 35 statements.

Once the number of statements is decided upon, the next step would be to define the scale to be used to sort the items, which is dependent on the number of statements itself. Brown (1980) gives some idea how it should be in practice: for example, up to 40 items - 9-point scale (from -4 to +4 ), for 40-60 items - 11-point scale $(-5$ to +5$)$, and for more than 60 statements -13 -point scale $(-6$ to +6$)$. A good approach would also be to think about kurtosis of semi-normal distribution (to make this pyramid flat or steep). In the same paper, Brown (1980) gives a pragmatic way of dealing with this: in the case of experts and a more complex topic of research, distribution should be flat; whereas in the case of simple research questions or the general public with limited knowledge on the topic, it could be a steeper distribution in order to allow respondents to put more indifferent opinions in the middle of the pyramid. In our pilot research, we decided to use a rather regular shaped semi-normal distribution with a 9-point scale, from -4 to +4 (Figure 1).

The chosen statements should present negative and positive, as well as neutral opinions on the topic; however, it is not necessary to have an exactly equal balance between the two, and nor does each positive statement require its exact negative

Figure 1. An example of a scale for collecting $\mathrm{Q}$ sorts.

\begin{tabular}{l|l|l|l|l|l|l|l|l|}
\hline-4 & -3 & -2 & -1 & +1 & & \\
\hline \\
\hline
\end{tabular}

Source: self-elaboration

statement to be present. This is because each statement bears, in fact, both opinions. For example, by marking a positive (in terms of its language) statement on an extremely negative scale, a respondent automatically indicates that he/she feels the exact opposite of it. Based on our experience, preparing neutral statements is a challenge because neutrality in itself is subjective and it is difficult to draft a sentence without any bias. Additionally, the statements should be drafted in such a way so that they can take into account opinions of as many groups of social categories related to the research topic as possible. In the case example, the different groups borne in mind while preparing the statements were government authorities (protected area officials, municipality officials, etc.), NGOs, and landowners.
Lastly, the statements should be written as simple, short phrases with one clear and distinct meaning that is consistent with the question/statement put at the beginning of the $Q$ statements. In our example, "biodiversity conservation on private land..." was the phrase, and each statement responded to it such as "...is possible, especially if it holds important biological resources." Also, to avoid restricting the opinion of the respondents, a pilot study similar to a regular questionnaire design and involving at least a couple of experts is imperative (Sztabiński, Sawiński, and Sztabiński 2005).

\section{Collecting the Q Sorts}

Once the statements are refined after the pilot study, the actual $\mathrm{Q}$ sorts can be collected. This step 
differs from regular questionnaire research in that, $\mathrm{Q}$ being a mixed method of quantitative and qualitative approach, conducting interviews also uses both approaches. It is a partially face-to-face standardized interview based on $\mathrm{Q}$ statements set and partially - in-depth interview in which responses of participants are enriched by additional comments.

It is preferable to conduct $Q$ study in a face-to-face interview, although online interviews are also possible. Participants are asked to sort all the statements along the prescribed distribution - from statements most disliked/disagreed through statements with neutral opinion, to most liked/agreed items. The result should be a pyramid of sorted statements, which will be then used in the next stage - data analysis.

"Forcing" participants to putting their own opinions in such a restricted picture could be frowned upon in a research methodology, especially with newer techniques such as conversational survey being proposed (Gobo 2011). Arguments against this "forced" method (Brown 1971; 1980; Bolland 1985) state that giving respondents a prescribed choice on sorting items have no effect on analysis (retrieving factors) and results. Additionally, using free distribution is more of a qualitative approach and provides better chances to discover true attitudes towards the given topic. However, arguments for using semi-normal distribution show that such free distribution could be too difficult for participants, and people generally prefer to have some clue on how to do this kind of sorting (Block 2008; Watts and Stenner 2012).
Using normal distribution has the biggest advantage since the standardized point of reference for all respondents makes results much easier to compare. We support this opinion - that forced distribution makes the whole procedure very usable and quite fast to gather data and then analyze it.

Choosing the number of respondents depends on two general rules. Firstly, $Q$ method treats respondents like variables, contrary to all $\mathrm{R}$ approaches that use conventional PCA/FA analysis. Hence, in $\mathrm{R}$ the statements would be the dependent variables, whereas in $\mathrm{Q}$ the respondents are the dependent variables. Following this rule, there should not be too many variables (participants) in order to make the analysis and results clearer. Secondly, $\mathrm{Q}$ methodology is not conclusive research and is not based on random sampling. Instead of number of respondents, it is more important to collect information from individuals with expertise and knowledge on the research topic. For example, in our case study, our focus was to cover different groups of stakeholders who represent subpopulations from three different forms of protected areas in Poland. However, Watts and Stenner (2012) provide some general advice on this matter. If the Q set number is about 60 items, $40-60$ participants are enough.

Collecting a $\mathrm{Q}$ sort involves two stages. The first step involves just the sorting of the statements by the respondents. For this step to be successful and efficient, participants should be provided with exact instruction on how to sort, an example of which is provided here:

Instructions for participants

[Background of the research and a brief project description are provided first.]

Each $\mathrm{Q}$ sort has 35 statements known as $\mathrm{Q}$ statements. As a respondent, you are expected to rank them on a scale of strongly agree to strongly disagree with a neutral/no opinion in the middle. Since $Q$ method limits the number of statements in each of its levels, please consider the statements that you feel are the strongest category. The scale ranges from +4 (strongly agree) to -4 (strongly disagree) with 0 indicating neutral/no opinion here.

The following guidelines might help you in sorting the statements:

- First, go through all the statements once, in order to know the diverse range of statements that are there and what the broad opinions that they generally express are.

- Sort the statements into three groups: one that you can agree with, one that you disagree with, and one that you have no opinion about.

- Once you have the three groups, go into one group at a time and start identifying the ones you feel very strongly about. It is very important to fill the extremes first, so start with the ones you completely agree/disagree with as the number of statements you can put in each rank is fixed.

- Once you have filled out the ones you are completely certain about, look at the statements you are left with one more time and try to put them in ranks. Again, it is important to start with the extreme (such as $-3,-2$ or $+3,+2$ ), and then move to the middle.

Once the sorting is done, additional open questions are put to the respondents about the method itself (how participants like this way of research) and about the statements - if they were clear, covered all points of view, anything that they would like to have added/modified, and so on. This helps to evaluate if respondents could sort the statements in a proper way that would represent their attitude. During piloting, such questions have crucial importance to make decision regarding potential changes in $\mathrm{Q}$ statements set. It is also advisable to gather some personal data (depending on the top- ic of research) of each respondent, which can later help in better interpretation of the results.

The second stage of collecting Q sorts should be conducted in a way similar to IDI interviews. During the sorting stage, it is allowed, and sometimes even important, to put questions on reasons for sorting particular items (like extreme agreement or disagreement, or items put in the middle). Any information gathered as additional comments or suggestions can be very important during the interpretation, as we show in discussion part. 


\section{Data Analysis and Interpretation}

\section{Data Analysis}

Once the desired number of $\mathrm{Q}$ sorts has been collected, the next step would be to choose adequate software to carry out the analysis. Two of the common software that caters specifically to $Q$ data are $\mathrm{PQ}$ method (available for free on the Internet for Windows and MacOS [on schmolck.userweb.mwn. de/qmethod/]) and PCQ (available for purchase). The data can also be analyzed with IBM SPSS Statistics, but it requires the data to be specifically prepared for this purpose and therefore, requires more effort. For our analysis, we used PQ Method, which is a self-explanatory software involving very simple steps. In this paper, we will not go into the details of using this software since it has already been done in Watts and Stenner (2012); instead, we will focus on obtaining the results and their proper interpretation.

The analysis of the data (through the software) is based on factor analysis (FA) or principal component analysis (PCA), and both methods produce similar results in this case. However, this method differs from regular $\mathrm{R}$ type FA/PCA because in the case of $Q$, the variables are the $Q$ sorts (as opposed to the statements) made by participants, whereas in regular $\mathrm{R}$ analysis, the statements form the variables, which are then evaluated by participants. This is because the goal of FA/PCA analysis of $\mathrm{Q}$ data is to simplify many participants' perspectives to some factors/components that will show some common attitudes of the investigated population. In contrast, the goal of $\mathrm{R}$ is to discover some latent dimensions of given attitudes towards given topic represented by statements.

Besides this basic difference, the FA/PCA procedure of $\mathrm{Q}$ method data is the same as regular FA/PCA Extraction of factors/components requires the researcher to make some decisions, such as choice of general extraction method (e.g., FA or PCA), number of factors/components to be extracted, and type of rotation of extracted factors/components. We avoid detailed description of each step of a FA/PCA, and instead will focus on obtaining the results by using the example of our pilot study.

Using our pilot data from 10 interviews, we conducted a principal component analysis. Based on Kaiser criteria of the factor's number, we decided to leave three factors solution (those with eigenvalue greater than 1). While deciding on how many factors/components to retrieve, it is important to remember that FA/PCA is an exploratory technique of data analysis in which the final results depend on clearness and interpretability of factors/ components. Hence, any criteria of limiting the number of factors should not be used without taking into account final result. In our case, the three factors were clearly understandable and characteristic, and so we decided to use all of them. In the next step, we used orthogonal rotation to make our three dimensions simpler and clearer. The decision to use rotation should be a pragmatic one. In our example, all three factors were very well built by the loading plots (represented by the sorts), and any non-orthogonal rotation did not make any impact on the results. So, we finally stayed with three factors rotated orthogonally.
Before we begin interpreting the data, it must be mentioned that the $\mathrm{PQ}$ method could be overwhelming in the case of data and tables it produces. Some of them are very important, while the others should be treated like additional information during interpretation. For our analysis, we relied on the following tables: factor matrix with rotated solution, factor arrays, distinguishing statements for each factor, and consensus statements.

Factor matrix with rotated solution is a table which bears information on which sorts contributed to each factor (marked by X symbol), for example, how many participants had common opinion on the different dimensions of the topic. We can see in our factor matrix table (see Appendix) that our example first factor was built by six respondents sorts, second by one (which is shortcoming of this factor, as discussed later), and third by three. The first factor explains 35\% variation of participants sorts, third $-22 \%$, and second $-12 \%$. We were satisfied with the contribution of each factor, and so we focused on factor arrays table and the tables that stated the distinguishing items for each. The factor arrays table represents scores of the statements as if it was a response of a person who loaded on that factor a hundred percent. Simultaneously, we also took into account the consensus statements table, and the purpose of doing this was to pay less emphasis on these statements (even if high ranked by a factor) because being a consensus statement meant it was put on more or less the same scale by each factor and therefore, was not helpful in distinguishing one from the other. However, we made a common interpretation of the consensus statements for ourselves, to highlight what all the respondents more or less agreed on.

\section{Factor Interpretation}

Using the factor arrays table (Table 1) and the distinguishing items table (example of which is provided in the Appendix), we followed Watts and Stenner's (2012) approach in preparing what they call a crib sheet. A crib sheet needs to be prepared individually for each factor. The first step is to separately list the statements with the most extreme score for that factor (from the factors array table). In our case, it were two statements for -4 and two for +4 . We did the same for -3 and +3 . Once we had the most extreme attitudes noted, we had to prepare two different categories. One was to note all statements (other than with the above mentioned scores) that ranked higher in this particular factor than in any of the other two factors. For example, a statement that scored 2 in Factor 1, but scored -1 and 0 in Factor 2 and 3 respectively. This category basically highlighted the statements that generated a more positive attitude towards the statement (but the statement itself could be negative in its content) from Factor 1 than Factor 2 or 3. Similarly, we used another category, which noted all statements in which Factor 1 scored lower than any other factor (e.g., Factor 1 scored at -1 , while Factor 2 and 3 put +1 and +2 respectively). This category highlighted statements that Factor 1 was more negative about than any other factors. These two categories of statements, together with the statement with the extreme scores, constituted the crib sheet. Additionally, the distinguishing factors table was consulted to note which statements hold the most importance in making this factor unique. In our analysis, we found that statements on the distinguishing table were usually already present in the crib sheet. The factor array table, along with our factor interpretations, is presented below. 
Table 1. Factor arrays table showing statements and the scores of each statement for each factor.
No. Statement

Factors

Biodiversity conservation on private land...

1 is possible, especially if it holds important biological resources. ity's decision to include it in a protected area.

3 at present, is supported by adequate compensation schemes for landowners whose benefits from land are compromised because of conservation.

will automatically transfer the same restrictions on the land to the next generation of owners of the land, which is big obligation.

5 implies that particular private land has important biodiversity and this is because management of that land has been well done thus far by landowners themselves.

6 at present, has no possible decision that satisfies every stakeholder/groups involved.

7. may put restrictions only on the use of the land, but it does not question the owners' right over their land. process in nature protection in Poland.

9 is possible, but this will require that all of the stakeholders have the opportunity to fully participate in the process of planning and management in nature protection.

would be more acceptable if a larger group of people from a given community is also willing to accept such restrictions on their land.

will require decisions on managing private land (those inside protected areas) to be made by the responsible conservation authorities as they have information on the whole protected area.

should be treated as one of the priorities in the process of developing nature conservation strat-

12 egies as elements of nature require continuous tracts of landscapes/ecosystems and sometimes

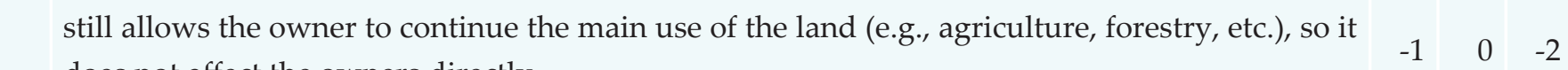
does not affect the owners directly.

14 does not change anything significantly about the functioning of the private land.

15 infringes on the rights of the owners over their own property.

takes away the final authority of the landowner in deciding what to do with his/her own land and this is the main reason that generates the conflict.

17 should be a voluntary action where the decision to participate is directly of the landowner only.
2 should consider landowners willingness to participate, and not just the administration/author-

8 is practically impossible to implement in the given state of management and decision making private land connects or is a part of such ecosystems.

\section{preparation or drafting of the plan.}

is an accepted form of biodiversity conservation that is prescribed from the EU or national policies, and so designation of protected areas do not require obligatory consent of landowners.

is also helpful for existing land use (such as agriculture being protected from pests) because 25 biodiversity on the land and current land use complement each other and one is needed for the other to function properly.

will impose/have the same restrictions as that of the protected area that it is part of and this should be acceptable.

could be beneficial for the landowners as it can generate new income opportunities (ecotourism etc.) by being a protected area.

30 negatively affects the income generation from private land.

requires only market based instruments and financial incentives to solve the conflicts related to private protected areas.

cannot be implemented (without conflicts) in the long-term through financial incentives and market instruments alone.

can have a stronger impact in convincing the larger community when it is evident that few

33 pilots/individuals in the community are benefiting from taking conservation measures on their land.

may stop traditional practices of land use which will be gradually lost in subsequent generations.

35 is a mirror image (in terms of management) of public protected areas: top-down. This mechanism of governance on private property cannot be successful. 
Below we provide the factor interpretation of our most significant factors based on the statements that load on that factor.

Factor 1 - Conservation is a need and a benefit, but needs some financial and policy support.

Participants loading on this factor strongly believe in the ecological significance of including private land in nature conservation strategies - they see it as an important requirement to protect landscape/ ecosystems in a continuous manner and therefore, support such initiative (12: $+4 ; 27:-2)$. In the case of private land that is being considered as a protected site, they consider landowners as having complete knowledge on good management practices that has retained the conservation potential of the land so far $(5:+1)$.

They do not perceive serious challenges or conflicting issues in implementing conservation on private land at an individual or landowners level, especially with respect to change in their traditional/cultural practices of land use, questioning their property rights, or negatively impacting their income generation from that land (34: -3, 15: -1; 30: $0)$. Instead, they see more benefits for landowners from their land becoming protected area - in that it would help the existing land use (the existing biodiversity complementing the existing land use) and it could also generate new income opportunities by being a PA, for example, through eco-tourism (29: $+2 ; 25:+1)$.

Therefore, the main problem identified is at policy level, with current state of environmental policies not being adequate to support such actions, and although effective implementation will require more than financial incentives and compensations, the almost non-existence of such financial tools as options makes the situation worse (20: $-4,3:-3,32$ $0)$. Also, the direct translation of regional/national policies to the local level is not well received by landowners, and thus makes it seem like a top-down involuntary approach, even if it might not be (24: -3 ; $35: 0 ; 23:-1)$.

To mitigate this, they suggest making the procedure voluntary wherever possible and to leave some authority over the planning (e.g., drafting process of management plans) and management of the land in the hands of the landowners (22: $-4 ; 2:+3,17:+1)$. They support a stronger collaboration between all stakeholder groups (including conservation authorities) to make the process more participatory $(9:+4$; 8: $0 ; 11: 0)$.

Factor 2 - Conserve when it is a dire necessity: people matter!

Participant believes that private land conservation is important when it holds important biological resources (such as rare/endangered flora and/or fauna species), but do not emphasize on making it a priority in nature conservation strategies as they feel it would prioritize nature over human needs (1: +4 , 12: $0 ; 27:+3)$.

In terms of challenges, the top-down decision making process of private land management is not identified as a potential problem (35: -4); rather, the focus is on the negative impact on income gener- ated from the land and possible cost of conservation (30: $+4,29:-2)$. Even if a scenario where impact on income is not considered, it would still put restrictions on the landowners in deciding what they would like to do on their land - that is a sense of loss of authority over the land (16: +2). They do not see conservation strategies particularly complementing the traditional land use practices (25: -3; 34: 0). Moreover, becoming a protected area is almost always in perpetuity, which means the same restrictions being transferred to subsequent generation of owners, which is a liability no one wants to take (4: +3$)$.

However, the participant addresses one of the challenges with its solution that is (according to him/her) already in place. Market based instruments and financial incentives are highlighted as the main solutions for conflict mitigation, and according to the respondent, the current state of compensation schemes is quite adequate $(3:+3$; 31 : +2 ). The overall emphasis is on the involvement of landowners in the site management and the entire decision making process (22: -4; 11: 0, 19: -3). However, this factor lays less emphasis on complete participation of landowners in developing management plans for protected areas, as compared to the other factors (9: -1).

This factor therefore understands why private land is important for biodiversity conservation, but thinks the risks and compromises are far too high for the landowners.

Factor 3-A mixed model of structure and functioning of conservation strategies: partner with authorities.
Participants loading on this factor accept private land conservation as an ecological, as well as biological need and therefore, believe in abiding by the policy prescription. They acknowledge the need for private land in biodiversity conservation because of its biological resources and ecological connectivity (1: $+2 ; 12:+2)$. As a result, in comparison to other participants, they are more willing to accept private land conservation as a translation of national and EU policies where site designation does not need obligatory consent of the landowners, and therefore, this step of the process does not necessarily have to be participatory (24: +1 ; $17:-3$; 23: -3$)$.

They, however, accept that the system of biodiversity conservation on private land is currently not supported by adequate policies at national and local level that will satisfy the needs of all groups (20: $-4 ; 6:+1)$. The main issues of contention and possible conflict in implementing conservation on private land (in addition to altering/restricting current land use) has been identified as infringement of property rights, or the perception of it (15: +3 ; 7 : -4; 13: -2; 14: -2). However, they do not link this to possible cultural loss or loss of traditional practices in the future; instead, they see new opportunities for income generation (34: -3 ; 18: +2$)$.

Participants loading on this factor do not emphasize as much on financial implications of conservation on landowners as compared to other participants - that is, they do not particularly think that income generation is drastically affected and that there is a serious need to focus on additional financial compensation for successful implementation (32: 0; 30: 0; 28: 0). They, instead, focus on 
effectiveness of mixed models of protected areas in both structure and functioning: structure as a mix of public and private land combined, and functioning as a mix of responsible (conservation) authorities and other local stakeholders collaborating and making the process more participatory $(9:+4 ; 19$ : +4 ; 21: 0). As compared to the other participants, they show more acknowledgement and are more willing to rely on the competence and importance of authoritative figures in the decision making process (11: +2; 22: -1)

\section{Discussion and Conclusions}

With human dimension in scientific research, Q methodology finds its way into many fields that extend beyond the conventional social sciences. It is our strong belief that $\mathrm{Q}$ methodology will be a useful tool to incorporate human subjectivity into such interdisciplinary studies as the one discussed in the example mentioned in this paper. It is a more sophisticated scale of measuring different human attitudes than other conventional scales, such as Likert's scale used in social sciences. Often, Q methodology is criticized on the ground that it limits and controls the respondents' opinions. It is important, however, to remember that because of this constraint it is possible to evaluate each statement with respect to the other, which makes it possible to draw an overall inference and co-relate opinions.

Conducting the Q study and completing its analysis is a fairly easy task, with the methodology being clearly defined and relatively easy to follow. The biggest challenge that we identify in conducting a $Q$ study is while preparing the $Q$ statements which actually determine the scale. Since every other step of the methodology is highly dependent on the statements, it is of utmost importance that the statements be as diverse, inclusive, and exhaustive as possible. Any form of biases, overlooking, or ignorance while drafting the statements could divert the study in one direction or another.

Although additional information on the respondents was not collected in the example mentioned in this paper because it was a pilot study, we would like to emphasize that such additional information (demographic, social, economic, ethnic, etc.) could be valuable aid in the interpretation process. Hence, it is advisable to note down any additional information that could potentially help in moments of uncertainty during the interpretation process.

During the data analysis for the pilot study, one of the challenges was in handling the amount of data generated by the DOS based PQ method software. For a novice, first-time user, it could be quite overwhelming. However, it is free software with good manuals and guides available in research papers, and the output from the software is easy to handle. Hence, once accustomed to the software, it is a relatively easy process from thereon. Analysis does not need any sophisticated statistical knowledge other than the basics of PCA/FA. Instead, more effort needs to be put in the qualitative interpretation of "hard" statistical results, where the experience of researcher and knowledge about topic are key factors.

While appreciating these quantitative advantages that this method provides, it also leaves a lot of room to include subjective opinions in the final interpretation by incorporating the respondents' subjective points of view, as well as researcher's observations and knowledge on the subject. Therefore, it combines the advantages of both qualitative and quantitative tools. However, this advantage is also a double-edged sword - it can result in researcher's bias being incorporated into the results. It is wise to be aware of this possibility and take precautionary approach to not let subjectivity take over the interpretation completely. We would also like to emphasize that due to the method of sample selection in a Q study (which is non-random), results cannot be statistically generalized for the whole population. However, it is possible to make some conclusions and interpretations taking into account the popula-

\section{References}

Block, Jack. 2008. The Q-Sort in Character Appraisal: Encoding Subjective Impressions of Persons Quantitatively. Washington, DC: American Psychological Association.

Bolland, John M. 1985. “The Search for Structure: An Alternative to the Forced Q-Sort Tchnique." Political Methodology 11(1/2):91-107.

Brown, Steve R. 1971. “The Forced-Free Distinction In Q Technique." Journal of Educational Measurement 8(4):283-287.

Brown, Steve R. 1980. Political Subjectivity: Applications of Q Methodology in Political Science. New Haven: Yale University Press.

Brown, Steve R. 1996. “Q Methodology and Qualitative Research." Health Research 6(4):561-567.

Cent, Joanna, Cordula Mertensa, and Krzysztof Niedziałkowski. 2013. “Roles and Impacts of Non-Governmental Organiza- tion under study. Such inference would not be conclusive, but the results may be useful in an exploratory or heuristic way in speaking about the given population.

In conclusion, empirical research requires hard statistical evidence to support a finding, and methodologies of qualitative data inherently lack in this due to the very nature and use of such methodologies. Q methodology supports the qualitative data on human subjectivity with some statistical evidence that supports the interpreted subjective view, but not how many people express this view. Therefore, it is still an exploratory tool, but with a quantitative base that gives otherwise qualitative data some statistical support. 
Grodzińska-Jurczak, Małgorzata. 2008. “Rethinking of Nature Conservation Policy in Poland: The Need of Human Dimensions Approach." Human Dimensions of Wildlife 13:380-381.

Grodzińska-Jurczak, Małgorzata and Joanna Cent. 2011. “Expansion of Nature Conservation Areas: Problems with Natura 2000 Implementation in Poland?" Environmental Management 47:11-27.

Grodzińska-Jurczak Małgorzata et al. 2012a. "Problemy społeczno-ekonomiczne przy wyznaczaniu obszarów Natura 2000 w Polsce." Teka Kom. Ochr. Kszt. Środ. Przyr. OL PAN w Lublinie 9:64-69.

Grodzińska-Jurczak, Małgorzata et al. 2012b. “Effectiveness of Nature Conservation - A Case of Natura 2000 Sites in Poland." Pp. 183-202 in Protected Area Management, edited by B. Sladonja. Rijeka: InTech.

Herberlein, Thomas A. 2012. Navigating Environmental Attitudes. New York: Oxford University Press.

Irwin, Alan. 2001. Sociology and the Environment. Cambridge: Polity Press.

Kerlinger, Fred N. 1969. Foundations of Behavioural Research: Educational and Psychological Enquiry. London: Holt, Rinehart and Wilson.

Maison, Dominika. 2007. “Jakościowe metody badań marketingowych." Pp. 4-25 in Badania marketingowe. Od teorii do praktyki, edited by D. Maison, A. Noga-Bogomilski. Gdansk: Gdańskie Wydawnictwo Psychologiczne.

Manfredo, Michel J., Jerry J. Vaske, and Daniel J. Decker. 1995. "Human Dimensions of Wildlife: Basic Concepts." Pp. 17-32 in Wildlife and Recreationists: Coexistence Through Management and Research, edited by R. Knight, K. Gutzwiller. Washington, DC: Island Press.

Manfredo, Michel J. and Ashley A. Dayer. 2004. "Concepts for Exploring the Social Aspects of Human-Wildlife Conflict in a Global Context." Human Dimensions of Wildlife 9:317-328.

Miles, Matthew B. and Michael A. Huberman. 1994. Qualitative Data Analysis: An Expanded Sourcebook. London: Sage.
Nijnik, Maria et al. 2010. “A Study of Stakeholder' Perspectives on Multi-Functional Forests in Europe." Forests, Trees and Livelihoods 19(4):1-18.

Pietrzyk-Kaszyńska, Agata et al. 2012. “Factors Influencing Perception of Protected Areas - The Case of Natura 2000 in Polish Carpathian Communities." Journal for Nature Conservation 20:284-292.

Ray, Lily. 2011. “Using Q-Methodology to Identify Local Perspectives on Wildfires in Two Koyukon Athabascan Communities in Rural Alaska." Sustainability: Science, Practice, \& Policy 7(2):18-29.

Sandbrook, Chris et al. 2010. "Value Plurality Among Conservation Professionals." Conservation Biology 25(2):285-294.

Sell, Deborah and Steven Brown. 1984. "Q Methodology as a Bridge Between Qualitative and Quantitative Research: Application to the Analysis of Attitude Change in Foreign Study Program Participants." Pp. 79-87 in Qualitative Research in Education, edited by J. L. Vacca, H. A. Johnson. Kent: Kent State University, Bureau of Educational Research and Service.

Shinebourne, Pnina. 2009. “Using Q Method in Qualitative Research." International Journal of Qualitative Methods 8(1):93-97.

Spurgeon, Laura et al. 2012. "A Q-Methodology Study of Patients' Subjective Experiences of TIA." Stroke Research and Treatment 2012:1-10.

Stainton Rogers, Rex. 1995. “Q Methodology." Pp. 178-193 in Re thinking Methods in Psychology, edited by J. A. Smith, R. Harre L. Van Langenhove. London: Sage.

Steelman, Toddi A. and Lynn A. Maguire. 1999. “Understanding Participants Perspectives: Q-Methodology in Nationa Forest Management." Journal of Policy Analysis and Management 18(3):361-388.

Stephenson, William. 1935. “Technique of Factor Analysis." Nature 136:297.

Sztabiński, Paweł B., Zbigniew Sawiński, and Franciszek Sztabiński. 2005. Fieldwork jest sztuka. Warsaw: Wydawnictwo IFiS PAN.
Van Exel, Job and Gjalt de Graaf. 2005. Q Methodology: A Sneak Preview. Retrieved May 30, 2014 (http://qmethod.org/articles/vanExel.pdf).

Watts, Simon and Paul Stenner. 2005. "The Subjective Experience of Partnership Love: A Q Methodological Study." British Journal of Social Psychology 44:85-107.

Watts, Simon and Paul Stenner. 2012. Doing Q Methodological Research. Theory, Method and Interpretation. London: Sage.
Webler, Thomas, Stentor Danielson, and Seth Tuler. 2009. Using Q Method to Reveal Social Perspectives in Environmental Research. Greenfield, MA: Social and Environmental Research Institute. Retrieved May 20, 2014 (http://www.seri-us.org/sites/default/ files/Qprimer.pdf).

Woods, Peter. 2006. Qualitative Research. University of Plymouth. Retrieved June 10, 2014 (http://www.edu plymouth.ac.uk/resined/qualitative\%20methods\%202/qualrshm.htm).

Kamal, Sristi, Marcin Kocór, and Małgorzata Grodzińska-Jurczak. 2014. "Quantifying Human Subjectivity Using Q Method: When Quality Meets Quantity." Qualitative Sociology Review 10(3):60-79. Retrieved Month, Year (http://www.qualitativesociologyreview.org/ENG/archive_eng.php).

\section{Appendix}

Factor matrix with an $\mathrm{x}$ indicating a defining sort.

\begin{tabular}{|c|c|c|c|}
\hline QSORT & \multicolumn{3}{|c|}{ Loadings } \\
\hline 1 stu1 & $0.8049 \mathrm{x}$ & 0.0168 & 0.4009 \\
\hline 2 stu2 & 0.3224 & -0.2751 & $0.7219 \mathrm{x}$ \\
\hline 3 stu3 & $0.5735 \mathrm{x}$ & 0.1101 & 0.5176 \\
\hline 4 stu4 & 0.1443 & $0.9391 \mathrm{x}$ & 0.0828 \\
\hline 5 stu5 & -0.0611 & 0.3722 & $0.7962 \mathrm{x}$ \\
\hline 6 stu6 & 0.5467 & -0.0306 & $0.5994 \mathrm{x}$ \\
\hline 7 stu7 & $0.8247 \mathrm{x}$ & 0.1048 & 0.0759 \\
\hline 8 stu8 & $0.8555 \mathrm{x}$ & 0.0827 & 0.1009 \\
\hline 9 stu9 & $0.6119 \mathrm{x}$ & -0.0211 & 0.4738 \\
\hline 10 stu10 & $0.5216 \mathrm{x}$ & -0.3440 & 0.1148 \\
\hline \% expl.Var. & 35 & 12 & 22 \\
\hline
\end{tabular}

Source: self-elaboration. 
Example of a distinguishing statements table (distinguishing statements for Factor 1).

Consensus statements - those that do not distinguish between ANY pair of Factors.

1

Should consider landowners willingness to partici-

No.

\section{Statement}

Should be treated as one of the priorities in the process of developing nature conservation strategies as elements of nature require continuous tracts of landscapes/ecosystems and sometimes private land connects or is a part of such ecosystems.

Requires stronger collaboration between the lo-

21 cal stakeholders and the agencies responsible for conservation of the area.

Implies that particular private land has important biodiversity and this is because management of that land has been well done thus far by landowners themselves.

Is also helpful for existing land use (such as agriculture being protected from pests) because

25 biodiversity on the land and its current land use complement each other and one is needed for the other to function properly.

17 Should be a voluntary action where the decision to participate is directly of the landowner only.

Cannot be implemented (without conflicts) in the

32 long-term through financial incentives and market instruments alone.

Requires only market based instruments and fi-

31 nancial incentives to solve the conflicts related to private protected areas.

Is an involuntary procedure imposed on landowners, and hence is unacceptable.

At present, is supported by adequate compensa-

3 tion schemes for landowners whose benefits from land are compromised because of conservation.

$\mathrm{P}<.05$; Asterisk (*) indicates significance at $\mathrm{P}<.01$.

Both the Factor Q-Sort Value (Q-SV) and the Z-Score (Z-SCR) are shown.

Source: self-elaboration

1.67
Factors

2

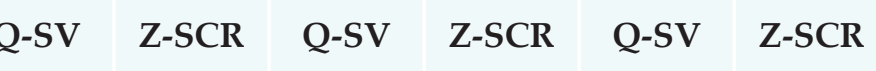

0.00

2

0.46 